\title{
Study on Human Obesity With Reference To Age, Gender, Body Mass Index and Blood Pressure
}

\author{
Nirmala Natarajan $^{1^{*}}$ and B.Elaveini ${ }^{1}$ \\ ${ }^{I}$ Research Department of Zoology, Periyar E.V.R. College (Autonomous), Tiruchirappalli, Tamil Nadu, India.
}

\begin{abstract}
This study was conducted in Obesity Research Clinic, Kasthuripuram, Tiruchirappalli 17. Healthy obese and non-obese male subjects with Body Mass Index (BMI) $18.5-24.9 \mathrm{~kg} / \mathrm{m}^{2}$ and 85 healthy obese and non-obese female with Body Mass Index of $25-29.9 \mathrm{~kg} / \mathrm{m}^{2}$, age group between $9-67$ years were selected. Parameters such as BMI, systolic and diastolic blood pressure were assessed. BMI was determined from the parameters such as weight and height; the subjects were classified as normal, overweight and obese. Hypertension was determined from the measure of blood pressure. The results show a consistence relation between BMI and hypertension within age groups in both male and female. The tables exhibited a relation of age with BMI and hypertension in both males and females subjects. The results showed a higher trend of hypertension with increasing BMI. In young females it was noticed that due to increased BMI the incidence of hypertension was very high.
\end{abstract}

Key words: Obesity, Body Mass Index, Blood Pressure, hypertension, Age, Gender.

\section{Introduction}

Demographic, economic, social and nutritional transitions that occurred in the past decades shifted public health paradigms worldwide in the form of growing prevalence of overweight and obesity in virtually all age groups. Obesity in children and adolescents is gradually becoming a major public health problem in India. Obesity has profound on a child life. This is prevalent in developing countries with a prevalence of obesity among children of low economic status [1]. The 1999 to 2002 National Health and Nutrition Examination Survey (NHANES) revealed that $16 \%$ of children between ages 6 and 19 are overweight [2]. In India the rising rates of obesity are associated with the transition from rural to urban lifestyles [3]. Totally $5 \%$ of the Indian population has been affected by obesity. Overweight and obesity are the fifth leading risk for global deaths. At least 2.8 million adults die each year as a result of being overweight or obese. In 2011, more than 40 million children under the age of five were overweight. More than 30 million overweight children are living in developing countries and 10 million in developed countries [4].

Outcomes related to child-hood obesity include hypertension, type 2 Diabetes Mellitus; Dyslipidaemia left ventricular hypertrophy, non-alcoholic steatohepatitis, obstructive sleep apnea, and Orthopaedic and psychosocial problems [5,6]. World Health Organization (WHO) defines overweight as a BMI equal to or more than 30 . By contrast, greater energy intake was associated with weight gain only among women. Thus population wide, the relationship of physical inactivity to weight gain appeared to be more consistent than the relationship of excess energy intake to weight gain [7]. Recently, the role of fat itself in the development of obesity and its consequences was considered to be a passive one adipocytes were considered to be little more than storage cells for fat [8]. Dietary fat content is directly correlated with energy intake, produces only weak satiation in comparison with protein and carbohydrate, and is thought to be processed efficiently by the body [9].

Obesity is becoming an increasingly important clinical and public health challenge throughout the world [10]. Recently, a number of studies have provided support for a link between the altered sleep/ wake patterns associated with our '24-hours' lifestyle and obesity. And the heart of the association between sleep and obesity may be a molecular mechanism intrinsic to all eukaryotic cells and organisms, namely the circardian clock [11]. Scientist have learned that genes can powerfully influence human eating behavior and that obesity at least in part, is a genetically determined disorder of appetitive behaviour. The pace of discovery is escalating and human genetics will play a crucial role in improving our understanding of basic energy regulation [12]. Individual responsibility can be assessed collectively only where people have access to a healthy lifestyle, and are supported to make health choices.

WHO emphasizes on the need of mobilization of stakeholders who can play a vital role in shaping healthy environments and shaping making healthier diet options affordable and easily accessible. Dietary factors do not appear to be the primary determinant of the increasing prevalence of obesity, By contrast, available longitudinal data point toward a potentially important contribution of reduced physical activity [13]. Any stress, including one such as trouble with relationships, causes anxiety and decreases pleasure and comfort. Serious and continuous failure of coping with stress influence the autonomic nervous function controlling homeostasis and 
the function of the endocrine system, and sometimes results in mental and somatic disease accompanied death [14]. "WHO Action Plan for the Global strategy for the prevention and control of Non-Communicable Diseases", provides a roadmap to establish and strengthen initiatives for the surveillance, prevention and management of non-communicable diseases, including obesity in low-and middle-income countries and its serious implication for poverty reduction and economic development. The purpose of this study was to observe and compare recent estimates of the prevalence of overweight and obesity among different age groups in Obesity Research Clinic, Kasthuripuram, Tiruchirappalli, and to examine the associations between Sex, BMI, and BP among obesity patients.

\subsection{Sample Collection}

\section{Materials And Methods}

The present study was conducted among obesity patients, in Obesity Research Clinic, Kasthuripuram, Tiruchirappalli. The study was conducted from Nov-2013 to Feb-2014. The Study population included obesity patients belonging to different regions of the country with varied socio-cultural practices and/or source of influence/knowledge. Among 168 patients, 83 (49.4\%) were males and 85 (50.6\%) were females. 29.2\% subjects were between the age groups 41-50. Simple Radom method was employed, and all obesity patients of the clinic were also included at subject for the study.

\subsection{Inclusion Criteria}

Healthy subjects who were willing to participate in the study from Periyar E.V.R College, Tiruchirappalli- 23, Tamil Nadu.

\subsection{Ethical Considerations}

Written informed consent was obtained from the study participants before obtaining any information from them. Utmost care was taken to maintain privacy and confidentiality. Patients were assured that results of the study will have no impact on their academics or personal life.

\subsection{Data Analysis}

Data entry and statistical analysis was done using SPSS version 20. Frequency distributions, percentages and chi- square test were calculated for all variables.

\section{Results}

The study was conducted to find out the association between Age, BMI and BP. It was presented in (Table $1-4)$. Out of 168 obesity patients, $83(49.4 \%)$ were males and $85(50.6 \%)$ were females. Majority (29.2\%) were between 41-50 years of age. Chi-square test for association between age group of patients and level of BMI was shown in Table-1. It was observed that if p-value is less than 0.05 the null hypothesis is rejected at $5 \%$ level of significance. Their exist a significant association between BMI level and age group of patients $\left(\chi^{2}=41.769, \mathrm{p}<0.05\right)$. Table-1 reveals that patients under the age group between 21- 60 years have the BMI level as $25-29.9 \mathrm{~kg} / \mathrm{m}^{2}$ (over weight) and $30-34.9 \mathrm{~kg} / \mathrm{m}^{2}$ (moderate obese) is $36.3 \%$ and $34.5 \%$ (totally $70.8 \%$ ) respectively, have been recorded.

The Chi-square test for association between age group of obesity patients and blood pressure was tabulated in Table-2. Since p-value is less than 0.01 the null hypothesis is rejected at $1 \%$ level of significance, their exist a significant association between blood pressure and age group of patients Chi-square $\left(\chi^{2}\right)$ value is 55.446, and p-value is 0.01 . Patients under the age group of below 20 to above 60 years having $2.4 \%$ of low BP, $33.3 \%$ of Normal BP, $32.7 \%$ of Pre hypertension, $20.2 \%$ of Stage I hypertension and $11.3 \%$ of Stage II hypertension. The same percentages have been recorded in Table-3, this table demonstrates about the ChiSquare test for association between BMI level of Obesity patients and Blood Pressure. In that table the p-value is less than 0.01 , the null hypothesis is rejected at $1 \%$ level of significance. Hence conclude that exist a significant association between BMI levels and Blood Pressure of patients $\left(\chi^{2}=43.824, p<0.01\right)$

The inter-correlation matrix between blood pressure, BMI level and age group of obesity patients was shown in Table-4. To find the direction of relationship between blood pressure, BMI level and age group, KarlPearson's correlation measure was applied. Higher the correlation, higher will be the relationship between variables and which in turn influences the blood pressure at a higher level. The table clearly shows that there is a significant positive relationship between the blood pressure, BMI level and Age group. Moderate and significant positive correlation exist between blood pressure and age, $\mathrm{r}=0.353, \mathrm{p}<0.01$ and BMI levels $(\mathrm{r}=0.341, \mathrm{p}<0.01)$. 
Study on Human Obesity With Reference To Age, Gender, Body Mass Index and Blood Pressure

Table -1. Chi- square test for association between age group of obesity patients and level of BMI

\begin{tabular}{|c|c|c|c|c|c|c|c|c|c|}
\hline \multirow{2}{*}{$\begin{array}{l}\text { Age group } \\
\text { (in years) }\end{array}$} & \multicolumn{6}{|c|}{ BMI LEVEL $\left(\mathrm{Kg} / \mathrm{m}^{2}\right)$} & \multirow{2}{*}{ Total } & \multirow{2}{*}{$\begin{array}{c}\text { Chi-square } \\
\text { Value }\end{array}$} & \multirow[t]{2}{*}{ p-value } \\
\hline & $18.5-24.9$ & 25-29.9 & $30-34.9$ & 35-39.9 & $40-44.9$ & Above 45 & & & \\
\hline \multirow[t]{2}{*}{ Below 20} & 6 & 8 & 11 & 0 & 0 & 2 & 27 & \multirow{14}{*}{41.769} & \multirow{14}{*}{ 0.019* } \\
\hline & $22.2 \%$ & $29.6 \%$ & $40.7 \%$ & $0.0 \%$ & $0.0 \%$ & $7.4 \%$ & $100.0 \%$ & & \\
\hline \multirow[t]{2}{*}{$21-30$} & 7 & 19 & 9 & 2 & 1 & 1 & 39 & & \\
\hline & $17.9 \%$ & $48.7 \%$ & $23.1 \%$ & $5.1 \%$ & $2.6 \%$ & $2.6 \%$ & $100.0 \%$ & & \\
\hline \multirow[t]{2}{*}{$31-40$} & 2 & 12 & 15 & 3 & 1 & 2 & 35 & & \\
\hline & $5.7 \%$ & $34.3 \%$ & $42.9 \%$ & $8.6 \%$ & $2.9 \%$ & $5.7 \%$ & $100.0 \%$ & & \\
\hline \multirow[t]{2}{*}{$41-50$} & 4 & 16 & 22 & 5 & 1 & 1 & 49 & & \\
\hline & $8.2 \%$ & $32.7 \%$ & $44.9 \%$ & $10.2 \%$ & $2.0 \%$ & $2.0 \%$ & $100.0 \%$ & & \\
\hline \multirow[t]{2}{*}{$51-60$} & 2 & 5 & 1 & 4 & 0 & 0 & 12 & & \\
\hline & $16.7 \%$ & $41.7 \%$ & $8.3 \%$ & $33.3 \%$ & $0.0 \%$ & $0.0 \%$ & $100.0 \%$ & & \\
\hline \multirow[t]{2}{*}{ Above 60} & 3 & 1 & 0 & 1 & 1 & 0 & 6 & & \\
\hline & $50.0 \%$ & $16.7 \%$ & $0.0 \%$ & $16.7 \%$ & $16.7 \%$ & $0.0 \%$ & $100.0 \%$ & & \\
\hline \multirow[t]{2}{*}{ Total } & 24 & 61 & 58 & 15 & 4 & 6 & 168 & & \\
\hline & $14.3 \%$ & $36.3 \%$ & $34.5 \%$ & $8.9 \%$ & $2.4 \%$ & $3.6 \%$ & $100.0 \%$ & & \\
\hline
\end{tabular}

* significant at 5\% level

Table - 2. Chi- square test for association between age group of obesity patients and blood pressure

\begin{tabular}{|c|c|c|c|c|c|c|c|c|}
\hline \multirow{2}{*}{$\begin{array}{c}\text { Age } \\
\text { group } \\
\text { (in years) }\end{array}$} & \multicolumn{5}{|c|}{ BLOOD PRESSURE ( mm/Hg) } & \multirow{2}{*}{ Total } & \multirow{2}{*}{$\begin{array}{c}\text { Chi- } \\
\text { square } \\
\text { value }\end{array}$} & \multirow{2}{*}{ p-value } \\
\hline & $\begin{array}{l}\text { Low } \\
\text { Bp }\end{array}$ & $\begin{array}{c}\text { Normal } \\
\text { Bp }\end{array}$ & $\begin{array}{c}\text { Pre - } \\
\text { Hypertension }\end{array}$ & $\begin{array}{c}\text { Stage - I } \\
\text { Hypertension }\end{array}$ & $\begin{array}{c}\text { Stage }- \text { II } \\
\text { Hypertension }\end{array}$ & & & \\
\hline \multirow[t]{2}{*}{ Below 20} & 1 & 20 & 4 & 1 & 1 & 27 & \multirow{14}{*}{55.446} & \multirow{14}{*}{$0.000 * *$} \\
\hline & $3.7 \%$ & $74.1 \%$ & $14.8 \%$ & $3.7 \%$ & $3.7 \%$ & $100.0 \%$ & & \\
\hline \multirow[t]{2}{*}{$21-30$} & 1 & 11 & 22 & 4 & 1 & 39 & & \\
\hline & $2.6 \%$ & $28.2 \%$ & $56.4 \%$ & $10.3 \%$ & $2.6 \%$ & $100.0 \%$ & & \\
\hline \multirow[t]{2}{*}{$31-40$} & 1 & 10 & 11 & 8 & 5 & 35 & & \\
\hline & $2.9 \%$ & $28.6 \%$ & $31.4 \%$ & $22.9 \%$ & $14.3 \%$ & $100.0 \%$ & & \\
\hline \multirow[t]{2}{*}{$41-50$} & 0 & 10 & 16 & 14 & 9 & 49 & & \\
\hline & $0 \%$ & $20.4 \%$ & $32.7 \%$ & $28.6 \%$ & $18.4 \%$ & $100.0 \%$ & & \\
\hline \multirow[t]{2}{*}{$51-60$} & 0 & 5 & 1 & 4 & 2 & 12 & & \\
\hline & $0 \%$ & $41.7 \%$ & $8.3 \%$ & $33.3 \%$ & $16.7 \%$ & $100.0 \%$ & & \\
\hline \multirow[t]{2}{*}{ Above 60} & 1 & 0 & 1 & 3 & 1 & 6 & & \\
\hline & $16.7 \%$ & $0 \%$ & $16.7 \%$ & $50.0 \%$ & $16.7 \%$ & $100.0 \%$ & & \\
\hline \multirow[t]{2}{*}{ Total } & 4 & 56 & 55 & 34 & 19 & 168 & & \\
\hline & $2.4 \%$ & $33.3 \%$ & $32.7 \%$ & $20.2 \%$ & $11.3 \%$ & $100.0 \%$ & & \\
\hline
\end{tabular}

Table - 3. Chi - square test for association between BMI level of obesity patients and blood pressure

\begin{tabular}{|c|c|c|c|c|c|c|c|c|}
\hline \multirow{2}{*}{$\begin{array}{c}\text { BMI } \\
\text { level } \\
\left(\mathbf{K g} / \mathbf{m}^{2}\right)\end{array}$} & \multicolumn{5}{|c|}{ BLOOD PRESSURE } & \multirow{2}{*}{ Total } & \multirow{2}{*}{$\begin{array}{c}\text { Chi-square } \\
\text { Value }\end{array}$} & \multirow{2}{*}{ p-value } \\
\hline & $\begin{array}{l}\text { Low } \\
\text { Bp }\end{array}$ & $\begin{array}{c}\text { Normal } \\
\text { Bp }\end{array}$ & $\begin{array}{c}\text { Pre- } \\
\text { Hypertension }\end{array}$ & $\begin{array}{c}\text { Stage I } \\
\text { Hypertension }\end{array}$ & $\begin{array}{c}\text { Stage II } \\
\text { Hypertension }\end{array}$ & & & \\
\hline \multirow[t]{2}{*}{$18.5-24.9$} & 1 & 15 & 5 & 2 & 1 & 24 & \multirow{14}{*}{43.824} & \multirow{14}{*}{$0.002 * *$} \\
\hline & $4.2 \%$ & $62.5 \%$ & $20.8 \%$ & $8.3 \%$ & $4.2 \%$ & $100.0 \%$ & & \\
\hline \multirow[t]{2}{*}{$25-29.9$} & 3 & 21 & 23 & 10 & 4 & 61 & & \\
\hline & $4.9 \%$ & $34.4 \%$ & $37.7 \%$ & $16.4 \%$ & $6.6 \%$ & $100.0 \%$ & & \\
\hline \multirow[t]{2}{*}{$30-34.9$} & 0 & 16 & 21 & 16 & 5 & 58 & & \\
\hline & $0 \%$ & $27.6 \%$ & $36.2 \%$ & $27.2 \%$ & $8.6 \%$ & $100.0 \%$ & & \\
\hline \multirow[t]{2}{*}{$35-39.9$} & 0 & 1 & 4 & 5 & 5 & 15 & & \\
\hline & $0 \%$ & $6.7 \%$ & $26.7 \%$ & $33.3 \%$ & $33.3 \%$ & $100.0 \%$ & & \\
\hline \multirow[t]{2}{*}{$40-44.9$} & 0 & 0 & 2 & 1 & 1 & 4 & & \\
\hline & $0 \%$ & $0 \%$ & $50.0 \%$ & $25.0 \%$ & $25.0 \%$ & $100.0 \%$ & & \\
\hline \multirow[t]{2}{*}{ Above 45} & 0 & 3 & 0 & 0 & 3 & 6 & & \\
\hline & $0 \%$ & $50.0 \%$ & $0 \%$ & $0 \%$ & $50.0 \%$ & $100.0 \%$ & & \\
\hline \multirow[t]{2}{*}{ Total } & 4 & 56 & 55 & 34 & 19 & 168 & & \\
\hline & $2.4 \%$ & $33.3 \%$ & $32.7 \%$ & $20.2 \%$ & $11.3 \%$ & $100.0 \%$ & & \\
\hline
\end{tabular}

$* *$ Significant at $1 \%$ level 
Table -4. Inter-correlation matrix between Blood pressure, BMI level and age group of obesity patients

\begin{tabular}{|l|c|c|c|}
\hline \multicolumn{1}{|c|}{ Factors } & Blood pressure & Age group & BMI - level \\
\hline Blood pressure & 1 & - & - \\
\hline Age group & $0.353(* *)$ & 1 & - \\
\hline BMI-level & $0.341(* *)$ & 0.068 & 1 \\
\hline \multicolumn{2}{|c|}{ Total $(\mathbf{N}=\mathbf{1 6 8})$} \\
\hline
\end{tabular}
** Correlation is significant at $\mathbf{0 . 0 1}$ level (2- tailed), $(\mathbf{p}<\mathbf{0 . 0 1})$.

\section{Discussion}

The process of rapid urbanization and changing lifestyles in India and other developing countries has brought obesity [15]. Obesity in adolescents and children has raised to significant levels globally with serious public health consequences. In addition to cardiovascular, emotional and social issues, it poses a serious hazard to the basic health care delivery systems [16].

In a last few decades, obesity has tripled and it has reached epidemic levels in developed countries [17]. The treatment of overweight and obesity in children and adolescents requires a multidisciplinary approach with a holistic outlook. The components of overweight and obesity treatment include dietary management, physical activity enhancement, and restriction of sedentary behavior, pharmacotherapy and batriatic surgery. The various phases of obesity management in ascending order of intensity include prevention oriented approach, structural weight management, comprehensive multidisciplinary intervention and tertiary care intervention. Compared with continuous exercise the intermittent exercise can oxidize the same amounts of lipids with less tiredness and less energy expenditure fatigue and monotony. [18]

The long term goal is to improve quality of life and reduction in morbidity as well as mortality, associated with overweight and obesity [19]. In the present study the results reveal that there is significant difference in the incidence of age, BMI, and BP. The study is carried out among the people residing in and around Tiruchirappalli, the two groups of obesity patient's one male and another female found to be similar in the distribution of age.

In the study it was also concluded that there is significant positive correlation relationship occurs between age and BMI, but obesity depends upon BMI $\left(\chi^{2}=41.769, p<0.05\right)$ According to BMI its values are defined as overweight or moderate, caused by family genes, effects of medication use, stressful life events, and other food habits.

Similar observations have been reported by a recent study population included $1^{\text {st }}$ year medical students, of medical college in Kancheepuram [20]. In their study, the total sample included 138 students, it was concluded that low income obese adolescents perceive obesity as a heritage, caused by family genes, side effects of medication use, and stressful life events.

In a study done in Germany it was reported that the intensity of physical activity played a critical role independent of age and gender in prevention of obesity. The prevalence of incident pre-hypertension and stage I hyper tension is recorded from age group of 21-30, 31-40, and 41-50 years of age. Stage 1 Hypertension was seen significantly higher percentages among $31-40$, and $41-50$ age groups $\left(\chi^{2}=55.446, p<0.01\right)$. The relationship has been reported by other studies as well hypertension is expected to begin occurring in overweight individuals [21]. In the present study, the results of BMI and BP reveals that if the BMI is under overweight (25-29.9) or moderate (30-34.9) and severe obese (35-39.9) then naturally the obesity patient's BP will reaches the level of pre hypertension and stage I hypertension [21]. $\left(\left(\chi^{2}=43.824, \mathrm{p}=0.01\right)\right.$

It was also reported that overweight children in Bogalusa heart study were 4.5 and 2.4 times as likely to have elevated systolic BP and diastolic BP respectively. Studies from India have also shown similar trends. People with binge eating over consumption alcohol may easily result in obesity and alcohol dependence accompanied by serious diseases [13]. Statistical analysis has been revealed that there is significant positive correlation is exist between BMI $(p<0.01)$ BP and age groups $(p<0.01)$.

The study had its limitations in the form that it was an obesity Research based study and thus result obtained from the study cannot be generalized to a specific community as the respondents were from varied geographical regions of the nation. In addition, all the obesity patients in the obesity Research clinic could have given much more comprehensive results.

\section{Conclusion}

The study revealed that through majority of the Obesity Patients were aware about the risk factors of Obesity there were many gaps identified in their knowledge which needs to be bridged. Obesity, Body Mass Index, and Blood Pressure had strongly positive correlation. As far Obesity is the major risk factor for Type 2 Diabetes, Cardio vascular Disease, and other related disorders and complications. It is possible to improve health, regular exercise, diabetic control by caloric restriction, weight loss and drug therapy were cited as the 
measure for prevention of development of Obesity. Results of the study implicate that there is an immense need to promote healthy lifestyles among the Obesity Patients for avoiding the premature onset of the lifestyle disorders.

\section{Acknowledgements}

The authors thank the Principal, Periyar E.V.R. College (Autonomous), Tiruchirappalli, Tamil Nadu, India for the encouragement and providing facilities for the study. And also the authors would like to acknowledge Dr. P.S. Mahadevan M.D, for granting permission to conduct this research in his Obesity Research Clinic, Kasthuripuram, Tiruchirappalli, Tamil Nadu, India.

\section{References}

[1] S. Singh, Rmlims, Prevalence of Obesity among school children of low socio economic status is much lesser then malnutrition. IOSR Journal of Humanities and Social Science, 3 (5), 2012, 32-34.

[2] J.J. Khan, Primary Steps for Handling Childhood Obesity. IOSR Journal of Dental and Medical Sciences 12, (2), 2013, 54-58.

[3] S. Shajithanoop, T. Periyasamy, and M.V.Usharani, Demographic Variations Influence obesity in a Semi - Urban Cohort of Tamil Nadu, South India. Journal of Life Science, 4(2), 2012, 87-95.

[4] K. Nageswari, R. Sharma, and D.R.Kohli, Assessment of Respiratory and Symphathetic Cardiovascular Parameters in Obese school Children. Indian Journal of Physiol Pharmacol, 51 (2), 2007, 235-243.

[5] S. Kaufman Jay, E. Owoaje Erne, A. James Sherman, N. Rotimi Charles S. Cooper Richard, Determination of hypertension in West Africa: Contribution of anthropometric and dietary factors of urban - rural and socio economic gradients. Am. J. Epidemiol, 143, 1996, 1203-1218.

[6] I.S. Okosun, R.S. Cooper, C.N. Rotimi, B. Osotimehin, and T. Forrester, Association of waist circumference with risk of hypertension and type 2 diabetes in Nigerians, Jamaicans and African Americans. Diabetes Care, 21, 1998,1832 - 1842.

[7] M.D. Weiner, L. Roland, R. Gary Hunter, F. Heini, I. Michael Goran and M. Shell, The Etiology of Obesity: Relative Contribution of Metabolic Factors, Diet, and Physical Activity. The American Journal of Medicine, 105, 1998, 145-150.

[8] S. Andrew, S. Greenberg, and S. Martin Obin, Obesity and the role of adipose tissue in inflammation and metabolism. American Journal of clinical Nutrition, 83(suppl), 2006, 4618 - 55.

[9] B. M. Popkin and A. Drewnowski, The nutrition transition: new trends in the global diet. Nutrition Reviews. 55 (2), $1997,31-43$.

[10] A. Nirmala, B.M. Reddy, and P.R. Reddy, Genetics of human Obesity: An Overview. International Journal of Human Genetics, 8 $(1-2), 2008,217-226$.

[11] M.S. Bray and M.E. Yong, Circardian Rhythms in the development of obesity potential role for the circardian clock within the adipocyte. The International Society for the study of obesity, Obesity reviews, 8, 2006, $169-181$.

[12] I.S. Farooqi and S.O. Rahilly, Genetic factors in human obesity. The international association for the study of obesity. Obesity Reviews 8, 2007 (suppl -1) 37-40.

[13] Akasabi, Nishikan ku and Niigata, Purpose in Life may improve Obesity caused by Stress: Proposal based on traits of Neurotransmitters related to emotions.IOSR Journal of Pharmacy, 2 (5), 2012, 05-07.

[14] A.J. Misra and L. Khurana, Obesity and metabolic syndrome in developing countries. Journal Clinical Endocrinol Metabolism, 93, 2008 (11 suppl -1): S 9-30.

[15] I. Nazeem, I. Siddiqui, and S. Bose, Prevalence and trends of obesity in Indian School Children of different socioeconomic class. Indian journal of Basic and Applied Medical Research, 2 (5), 2012.393-398.

[16] S. Shrivastava, I. Siddiqui and S. Bose. Prevalence and trends of Obesity in Indian School Children of different socioeconomic class. Indian Journal of Basic and Applied Medical Research, 2(5), 2012.393-398.

[17] Mohamed Ali Khanfir, Hassen Ben Aouicha, Liwa Masmoudi, Faten Ben Hmadou. Lipid Oxidation and perceived exertion level during exercise in Obese: effect of the exercise form. IOSR Journal of Pharmacy and Biological Sciences, 1(6), 2013, 45-50.

[18] Manu Raj, K.R. Sundaram, Mary Paul, A.S. Deepa and R. Krishna Kumar. Obesity in Indian Children: Time trends and Relationship with hypertension. The National Medical Journal of India, 20, 2007, 6.

[19] R.S. Tshalibe, N. Ndlovu, T. Usai, C. Makamure, D. Chinofunga, B. Mutonhodza and S.T. Kawadza. Overweight and Obesity Categories of Residents in A Local Urban Area. IOSR Journal of Environmental Science, Toxicology and Food Technology, 8(2), 2012, 77-81.

[20] B. Rosner, R. Prineas, S. R. Daniels and J. Loggie. Blood Pressure differences between blacks and whites in relation to body size among US Children and adolescents. American Journal Epidemiol, 151,2000, 1007-19.

[21] D.S. Freedman, W.H. Dietz, S.R. Srinivasan and G.S. Berenson. The relation of overweight to Cardiovascular risk factors among Children and adolescents. The Bogalusa Heart Study. Pediatrics, 103, 1999, 1175-82. 